\title{
German Heart Surgery Report 2018: The Annual Updated Registry of the German Society for Thoracic and Cardiovascular Surgery
}

\author{
Andreas Beckmann ${ }^{1}$ Renate Meyer ${ }^{2}$ Jana Lewandowski ${ }^{1}$ Andreas Markewitz ${ }^{1}$ Wolfgang Harringer ${ }^{3}$ \\ ${ }^{1}$ German Society for Thoracic and Cardiovascular Surgery, \\ Langenbeck-Virchow-Haus, Berlin, Germany \\ 2 BQS Institute for Quality and Patient Safety, Düsseldorf, Germany \\ ${ }^{3}$ Clinic for Cardiac, Thoracic and Vascular Surgery, Klinikum \\ Braunschweig GmbH, Braunschweig, Germany \\ Address for correspondence Dr. med. Andreas Beckmann, Deutsche \\ Gesellschaft für, Thorax-, Herz- und Gefäßchirurgie (DGTHG), \\ Langenbeck-Virchow-Haus, Luisenstr. 58-59, 10117 Berlin, Germany \\ (e-mail: gf@dgthg.de).
}

Thorac Cardiovasc Surg 2019;67:331-344.

\begin{abstract}
Based on a longtime voluntary registry, founded by the German Society for Thoracic and Cardiovascular Surgery (GSTCVS), well-defined data of all cardiac, thoracic, and vascular surgery procedures performed in 78 German heart surgery departments during the year 2018 are analyzed. For this period, a total of 174,902 procedures were submitted to the registry, 98,707 summarized as heart surgery procedures in the

Keyword

- heart valve procedures

- heart surgery

- mortality

- congenital heart disease

- coronary heart disease

- aorta surgery

- coronary artery bypass grafting

- heart and lung transplantation classical meaning. The unadjusted in-hospital survival rate for 33,999 isolated coronary artery bypass grafting procedures (relationship on-/off-pump 3.8:1) was $97.1 \%$ and for 34,915 isolated heart valve procedures, 14,396 transcatheter interventions included, it was $96.0 \%$. Concerning short- and long-term circulatory supports, a total of 2,871 extracorporeal life support (ECLS)/extracorporeal membrane oxygenation (ECMO) implants, respectively, 942 assist device implantations (L-/R-/BVAD, TAH) were registered. In 2018, the number of isolated heart transplantations increased to 312 , a growth of $23 \%$ compared with the previous year. The isolated lung transplantations reached 340 , a rise of nearly $19 \%$. This annual updated registry of the GSTCVS represents voluntary public reporting by accumulating actual information for nearly all heart surgical procedures in Germany, constitutes advancements in heart medicine, and is a basis for quality management for all participating institutions. In addition, the registry demonstrates that the provision of cardiac surgery in Germany is appropriate and nationwide patient treatment is guaranteed all the time.
\end{abstract}

\section{Introduction}

Legitimate demands for a sophisticated quality management in medicine-by authorities, scientific organizations, health care companies, and patients all over the world-have stimulated a quality awareness, resulting in the development of versatile quality assurance activities such as benchmark projects, public reporting, registries, and others to answer those needs. Thirty years ago, the board of directors of the
German Society for Thoracic and Cardiovascular Surgery (GSTCVS, www.dgthg.de) decided to set up a periodic data collection of all cardiac surgical procedures in terms of a voluntary unaudited registry. ${ }^{1,2}$ Since 1989 , the data are updated annually, summarized in sense of a registry, and published in the scientific society journal each year. ${ }^{3-7}$ The prevalent aims are: to detect developments and upcoming trends in cardiac surgery in Germany; to compile various results for nearly all cardiac surgical procedures; to received

May 20, 2019

accepted after revision

May 20, 2019
(C) 2019 Georg Thieme Verlag KG Stuttgart · New York
DOI https://doi.org/ 10.1055/s-0039-1693022. ISSN 0171-6425. 
provide each participant with a benchmark of the institutional results to the nationwide achievements; and to facilitate an evaluation on an international level for the German society.

For monitoring actual conditions as well as developments in cardiac medicine, the registry covers all relevant techniques and also innovative technologies, including minimally invasive cardiac surgery and all kinds of heart valve procedures, including transcatheter aortic valve implantation (TAVI). Thereby, important findings for current patient safety and the future of patient care are collected for evaluation under different aspects.

Data and results presented in this report comprehend assorted findings of the year 2018.

\section{Materials and Methods}

Since 2004, a standardized questionnaire gathers specific information for well-defined procedures exactly described by an annually updated German adaption of the International Classification of Procedures in Medicine called operation code (Operationen- und Prozedurenschlüssel).

All participating institutions were requested to complete the structured questionnaire by January 21, 2019, entering all performed procedures and associated in-hospital mortality. The recommended path for data export is an electronic transmission of an encrypted file to the society office in Berlin. After transaction, the data were decrypted, evaluated for completeness, and compiled for further analysis, thus ensuring anonymity for each participating institution. This compilation algorithm enables a high compliance for submission of complete datasets.

Inclusion criteria for the registry data 2018 were all cardiac surgical procedures performed on patients between January 1, 2018, and December 31, 2018, unrelated to the date of patients' admission or discharge as compared with other registries. Like in the earlier years, the number of procedures was counted rather than individual patients. For example, if a patient initially required isolated coronary artery bypass grafting (CABG), later followed by a mitral valve reconstruction due to an undesirable event, one count in the category "coronary surgery" and a second one in the category "mitral valve reconstruction" are enumerated. Thus, the registry contains more procedures than the real number of patients operated on.

Death of patients was defined as in-hospital mortality. Per definition, the observed mortality is always attributed to the first cardiac procedure, for example, the death of a patient requiring a replacement of the ascending aorta due to a complication after CABG would only be attributed to the coronary procedure.

The main reason for this structural setup of the registryestablished over three decades-is to keep in accordance with the German data privacy act with its specific regulations for patients. Furthermore, it seemed to be relevant to get detailed information about all performed procedures and not only the count of treated patients. Last but not least, the process of data acquisition had to be standardized and feasible for all participating departments in Germany, thus enabling the submission of a complete dataset, regardless of the locally existing hard- and software used.

In 2018, a total of 78 institutions performed heart surgery. As always, all departments answered the questionnaire and delivered a complete dataset for the year 2018 including in-hospital mortality rates. In addition, comparisons between the registry data and the external quality assurance in accordance with $\S \S 135 a / 136 / 137$ SGB V, obligatory for licensed German hospitals ( $§ 108$ SGB V), are feasible.

For statistical analyses, categorized tables and a summary registry data file consolidate all transmitted information of the 78 departments, providing the basis for this and further publications. Longitudinal data from earlier registry specifications are also included in the presentation. The period considered is restricted to the past 10 years.

Categorical data are displayed as absolute and/or relative frequencies. Due to the lack of complete data for patients' risk adjustment, all mortality rates are unadjusted. Quantitative data are presented as absolute frequencies and arithmetic mean values. Where appropriate, the value range is presented additionally. Patient age, though originally a quantitative variable, is only available in age groups and therefore treated as a categorical variable. German population-based measures are calculated as frequencies per 100,000 inhabitants and are based on the latest published data of the Federal Office for Statistics (Destatis) from November 30, 2018.

The questionnaires were compiled using Microsoft Visual Basic for Applications. Analyses were performed with IBM SPSS Statistics v22 and Microsoft Excel 2010, and charts and tables were created with Microsoft Excel 2010.

\section{Registry Data 2018}

- Table 1 shows the distribution of cardiac surgical procedures between the 16 German states, based on the population count of the Federal Office for Statistics as of November 30, 2018. The range of heart operations per 100,000 inhabitants again shows a minimum of 102.1 (Baden Württemberg, population: 11,076,352) and a maximum of 165.3 (Sachsen-Anhalt, population: 2,209,938), while the nationwide mean value was 117.9 (2017: 122.0). Analyzing quantified categories of heart operations by department dimension, nearly $67 \%$ of institutions are in two clusters with at least 518 up to 1,480 procedures, and $26 \%$ in those with a minimum of 1,569 up to a maximum of 3,872 performed procedures (-Table 2 ). Summarizing the departments by various heart surgical procedures, it can be asserted that heart operations in patients for congenital heart disease $(<1$ year, with extracorporeal circulation [ECC]) are conducted in 22, isolated heart transplantations in 20, and combined heart-lung transplantations in 2 institutions (-Table 3 ). The number of procedures using ECC in Germany from 2009 to 2018 is illustrated in - Table 4. Over the past decade, the number of heart operations using ECC shows a decline by 14,585 procedures, presumably reflecting an achievement of 
established innovations such as catheter-based procedures in cardiac medicine and minimally invasive therapeutic options in heart surgery.

Overall, 174,902 procedures were reported to the registry for the year 2018, a decrease of 2.5\% (2017: 179,337 procedures). In 2018, a total of 98,707 heart surgical procedures in the narrower sense display a decline of $3.0 \%(n=3,021)$ compared with 2017 (101,728 procedures) ( - Table 5). Concerning gender distribution, the registry shows an overall male:female ratio of 1.9:1 with the greatest distinction (3.3:1) in the patient group of coronary procedures ( Table 6); $11.3 \%(n=11,147)$ of the operations were conducted as emergency procedures, and $8.8 \%(n=8,642)$ were reoperations ( - Table 7). A total of $16,840(48.2 \%)$ isolated heart valve procedures were performed as single, 3,233 as double (9.3\%), and $353(1.0 \%)$ as triple valve procedures (-Table V1); 7,021 (41.7\%) single heart valve operations were performed via a minimally invasive access (-Table V2). In 8,800 (87.8\%) isolated aortic valve operations under ECC conditions, xenograft prostheses were implanted, while in 3,999 (64.3\%) isolated mitral valve operations, a reconstruction with preservation of the native valve could be achieved ( $\mathbf{- T a b l e ~ V 3 , ~ - ~ F i g s . ~} 5$ and $\mathbf{7}$ ). The subdivision of 3,586 multiple heart valve procedures led to 3,014 (84.0) operations, as a combination of mitral + tricuspid $(n=1,607)$ or mitral + aortic $(n=1,407)$ valve procedures ( - Tables V4 and V5).

- Tables V6, C1, C2, Con1, Con2, and Mis1 to Mis5 as well as -Figs. 1-4, 6, 8-10 demonstrate further compiled registry data under different aspects and for various categories.

Compared with the data of previous years, several important developments remained almost unchanged in 2018. The age distribution of patients ( - Fig. 3 ) shows a continuous shift toward an elderly patient population, with presently $34.8 \%$ of the cardiac procedures being performed in patients from 70 to 79 years of age, and $17.6 \%$ in octo-/ nonagenarians. However, unadjusted mortality rates remain on the same low level over the past decade (-Fig. 2). The number of CABG procedures, isolated or combined, decreased over the past decade, while the relative count for isolated off-pump CABG has now reached a level of 20.6\% (2017: 19.4\%) (-Figs. 1 and 4).

There is still a continuous increase of transcatheter heart valve procedures in Germany (-Table V6). In 2018, a total of 13,279 (57.5\%) TAVI procedures and 9,829 (42.5\%) surgical aortic valve replacements were reported to the registry (-Fig. 6). It must be emphasized that exclusively the German departments for cardiac surgery contribute their data and therefore the registry cannot reach completeness by the way of exception. On the basis of and in addition to the recommendations of international scientific guidelines resp. expert consensus on the management of valvular heart disease, ${ }^{8-11}$ in July 2015, the German Federal Joint Committee (G-BA) implemented a quality assurance directive for "minimally invasive heart valve interventions (TAVI, transcatheter mitral clip reconstruction)," in which obligatory structures, defined processes, and qualified personnel are precisely specified. ${ }^{12}$ Further surveys for selected procedures, such as the legally compulsory quality assurance ( $\$ 135 \mathrm{a}$ SGB V) or the voluntary nationwide German Aortic Valve Registry, ${ }^{13-18}$ provide various important findings and thus contribute to an exceptional patient benefit.

In 2018, the rate of mitral valve reconstructions shows a slight increase to $64.3 \%$ (2017: 63.7\%) (-Fig. 7). Based on the fact that each isolated mitral valve procedure is included, regardless of the underlying valve disease concerning morphology or urgency of operation, it can be assumed that the relative rate of mitral valve reconstruction would certainly be even higher if patients without a possibility or indication for reconstruction would have been excluded (e.g., mitral valve stenosis, calcifications, or endocarditis). In other publications, for example, Gammie et al, ${ }^{19}$ patients with mitral valve stenosis, endocarditis, and emergency procedures are usually excluded. Therefore, the published rates of mitral valve repair have to be interpreted with caution if compared with this registry.

In 2018, the ventricular assist device (L-/R-/BVAD, TAH) implantations $(n=942)$ showed a decrease of $8.2 \%$ compared with $2017(n=1,027)$ (-Fig. 9), while the heart transplantations $(n=312)$ reached the highest level for the past 5 years ( $\mathbf{- F i g}$. 10). Nevertheless, the mechanical circulatory support therapy, in particular LVAD, is still of outstanding importance for patients with end-stage heart failure.

\section{Discussion}

The registry of the GSTCVS enables a comprehensive overview of all heart surgical procedures performed in Germany in 2018. The accuracy of this registry is considered to be high due to the implemented compilation algorithm using standardized operation coding as a relevant criterion for reimbursement purposes. This is supported by other authors who could demonstrate a high accuracy for major outcome parameters in unaudited registries. ${ }^{20}$ As observed in recent years, heart surgery in Germany is continuously performed on a high level with superior in-hospital patient survival compared with international surveys. In addition, the registry demonstrates that the provision of cardiac surgery in Germany is appropriate, and that patient care is guaranteed nationwide at all times (24/7/365). These aspects are especially important in the context of various activities in health care policy and considering the background of demographic trends of the German population, leading to patients at increased age combined with related comorbidities and an accordingly complex preoperative risk profile.

Compared with 2017, the number of cardiac surgery procedures showed a disproportionate decrease for coronary artery bypass procedures, a curious trend in view of the German population characteristics and in the context of application of the scientific guidelines. ${ }^{21,22}$ Otherwise, the remarkable increase in heart transplantations is a 
reason for hope that this positive development will continue.

Further improvements of the registry are recommended to enable more specified assessments and particularly risk-adjusted data analyses. However, if significant fundamental changes related to the modality of data collection are conducted, it has to be considered that data compatibility will still allow further longitudinal data analysis.

Completeness, validity, and further progress depend on continued efforts and a close collaboration of the GSTCVS and all cardiac surgical departments in Germany. This will be of outstanding importance as a contribution for patient safety and to obtain evidence for the high quality of heart surgery in Germany.

Conflict of Interest

None.

\section{Acknowledgments}

The German Society for Thoracic and Cardiovascular Surgery would like to thank all heads of the departments for cardiac surgery in Germany and their employees for their continued cooperation and support to realize the annual update of this registry.

\section{Abbreviations}

ASD atrial septal defect

AVC Atrioventricular canal

CABG coronary artery bypass grafting

CHD congenital heart disease

DLTx double lung transplantation

DORV double outlet right ventricle

ECC extracorporeal circulation

ECLS extracorporal life support

ECMO extracorporal membrane oxygenation

HLTx heart-lung transplantation

HTx heart transplantation

ICD implantable cardioverter defibrillator

LTX lung transplantation

PDA patent ductus arteriosus

PTS patients

SAVR surgical aortic valve replacement

SLTX single lung transplantation

TAH total artificial heart

TAVI transcatheter aortic valve implantation

TGA transposition of great arteries

TMLR transmyocardial laser revascularization Tx transplantation

VADs ventricular assist devices

VSD ventricular septal defect

\section{Tables and Figures}

Table 1 Heart operations/German states

\begin{tabular}{|l|l|l|l|}
\hline Federal state & Quantity $^{\text {a }}$ & Population $^{\text {b }}$ & Heart procedures/100,000 inhabitants \\
\hline Baden Württemberg & 11,306 & $11,076,352$ & 102.1 \\
\hline Bayern & 13,690 & $13,082,541$ & 104.6 \\
\hline Berlin & 3,923 & $3,644,998$ & 107.6 \\
\hline Brandenburg & 3,414 & $2,511,943$ & 135.9 \\
\hline Bremen & 799 & 682,947 & 117.0 \\
\hline Hamburg & 2,232 & $1,841,484$ & 121.2 \\
\hline Hessen & 7,395 & $6,268,099$ & 118.0 \\
\hline Mecklenburg-Vorpommern & 2,266 & $1,610,280$ & 140.7 \\
\hline Niedersachsen & 10,235 & $7,984,849$ & 128.2 \\
\hline Nordrhein-Westfalen & 20,610 & $17,932,567$ & 114.9 \\
\hline Rheinland-Pfalz & $4,085,831$ & 125.3 \\
\hline Saarland & 5,119 & 991,116 & 132.5 \\
\hline Sachsen & 1,313 & $4,079,703$ & 125.2 \\
\hline Sachsen-Anhalt & 5,107 & $2,209,938$ & 165.3 \\
\hline Schleswig-Holstein & 3,653 & $2,897,035$ & 138.2 \\
\hline Thüringen & 4,005 & $2,144,446$ & 134.1 \\
\hline Germany & 2,876 & $\mathbf{8 3 , 0 4 4 , 1 2 9}$ & $\mathbf{1 1 7 . 9}$ \\
\hline
\end{tabular}

${ }^{a} n=764$ foreign residents excluded.

${ }^{b}$ Federal Office for Statistics of German: Population; due date November 30, 2018. 
Table 2 Departments assorted by quantified categories $\left(\sum^{\mathrm{a}}[n=98,707]\right)$

\begin{tabular}{|l|l|l|l|l|l|}
\hline Procedures (quantity) & $<500$ & $500-999$ & $1,000-1,499$ & $1,500-1,999$ & $2,000-5,000$ \\
\hline Departments & 6 & 25 & 27 & 10 & 10 \\
\hline Average & 367 & 789 & 1,190 & 1,750 & 2,716 \\
\hline Range & $225-475$ & $518-991$ & $1,004-1,480$ & $1,569-1,941$ & $2,023-3,872$ \\
\hline
\end{tabular}

aPacemaker/implantable cardioverter-defibrillator and extracardiac surgery without extracorporeal circulation are excluded.

Table 3 Departments summarized by heart surgery procedures 2018

\begin{tabular}{|l|l|}
\hline Category & N \\
\hline Coronary artery bypass grafting & 77 \\
\hline Heart valve surgery & 77 \\
\hline Surgery for CHD in pat. $<1$ y with ECC & $22^{\text {a }}$ \\
\hline Heart transplantation & $20^{\text {b }}$ \\
\hline Heart-lung transplantation & 2 \\
\hline
\end{tabular}

${ }^{a} N=2,086$ : thereof: 6 to 16 operations in 2 units, 25 to 49 operations in 6 units, 58 to 97 operations in 4 units, and 109 to 234 operations in 10 units ${ }^{\mathrm{b}} \mathrm{N}=312$ : thereof: 1 to 4 transplants in six units, 6 to 9 transplants in three units, 10 to 19 transplants in six units, and 21 to 81 transplants in five units.

Table 4 Cardiac procedures using extracorporeal circulation (2009-2018)

\begin{tabular}{|l|l|l|l|l|l|l|l|l|l|l|}
\hline & $\mathbf{2 0 0 9}$ & $\mathbf{2 0 1 0}$ & $\mathbf{2 0 1 1}$ & $\mathbf{2 0 1 2}$ & $\mathbf{2 0 1 3}$ & $\mathbf{2 0 1 4}$ & $\mathbf{2 0 1 5}$ & $\mathbf{2 0 1 6}$ & $\mathbf{2 0 1 7}$ & $\mathbf{2 0 1 8}$ \\
\hline Departments & 80 & 79 & 78 & 79 & 79 & 78 & 78 & 78 & 78 & 78 \\
\hline Operations & 86,916 & 84,686 & 84,402 & 84,388 & 84,040 & 83,787 & 81,527 & 79,082 & 76,696 & 72,331 \\
\hline Average & 1,086 & 1,072 & 1,082 & 1,068 & 1,064 & 1,074 & 1,045 & 1,014 & 983 & 927 \\
\hline
\end{tabular}

Table 5 Frequency of cardiac procedures 2018

\begin{tabular}{|l|l|l|l|l|}
\hline Category & $\begin{array}{l}\text { With } \\
\text { ECC }\end{array}$ & $\begin{array}{l}\text { Without } \\
\text { ECC }\end{array}$ & Total & $\begin{array}{l}\text { Difference } \\
2017(\%)\end{array}$ \\
\hline $\begin{array}{l}\text { Coronary artery } \\
\text { bypass grafting }\end{array}$ & $37,051^{\mathrm{a}}$ & $7,219^{\mathrm{a}}$ & 44,270 & -7.1 \\
\hline $\begin{array}{l}\text { Heart valve } \\
\text { procedures }\end{array}$ & $20,671^{\mathrm{a}}$ & $14,244^{\mathrm{a}}$ & 34,915 & +1.5 \\
\hline $\begin{array}{l}\text { Surgery of } \\
\text { thoracic aorta }\end{array}$ & $7,562^{\mathrm{a}}$ & $607^{\mathrm{a}}$ & 8,169 & -0.6 \\
\hline $\begin{array}{l}\text { Surgery } \\
\text { for CHD }\end{array}$ & $4,882^{\mathrm{a}}$ & $971^{\mathrm{a}}$ & 5,853 & -1.0 \\
\hline $\begin{array}{l}\text { Cardiac } \\
\text { surgery, other }\end{array}$ & $1,119^{\mathrm{a}}$ & $1,229^{\mathrm{a}}$ & 2,348 & +6.7 \\
\hline $\begin{array}{l}\text { Assist device } \\
\text { procedures }\end{array}$ & $656^{\mathrm{a}}$ & $2,106^{\mathrm{a}}$ & 2,762 & -5.1 \\
\hline $\begin{array}{l}\text { Extracardiac } \\
\text { surgery }\end{array}$ & $355^{\mathrm{a}}$ & 53,788 & 54,143 & -1.2 \\
\hline $\begin{array}{l}\text { Pacemaker and } \\
\text { ICD procedures }\end{array}$ & $35^{\mathrm{a}}$ & 22,407 & 22,442 & -3.3 \\
\hline Total & 72,331 & 102,571 & 174,902 & -2.5 \\
\hline
\end{tabular}

aSum: $n=98,707$ (heart surgery procedures).
Table 6 Gender distribution 2018

\begin{tabular}{|l|l|l|l|l|}
\hline \multirow{2}{*}{ Distribution } & \multicolumn{2}{l|}{ Female } & \multicolumn{2}{l|}{ Male } \\
\cline { 2 - 5 } & $N$ & $\%$ & $N$ & $\%$ \\
\hline Heart valve procedures & 15,132 & 43 & 19,783 & 57 \\
\hline Coronary procedures & 10,220 & 23 & 34,050 & 77 \\
\hline CHD procedures & 2,624 & 45 & 3,229 & 55 \\
\hline $\begin{array}{l}\text { Surgery of thoracic } \\
\text { aorta }\end{array}$ & 2,828 & 35 & 5,341 & 65 \\
\hline Cardiac surgery, other & 1,323 & 56 & 1,025 & 44 \\
\hline Assist device & 749 & 27 & 2,013 & 73 \\
\hline Pacemaker and ICD & 8,451 & 38 & 13,991 & 62 \\
\hline Extracardiac surgery & 18,949 & 35 & 35,194 & 65 \\
\hline Total & 60,276 & 34 & 114,626 & 66 \\
\hline
\end{tabular}

Table 7 Additional data 2018 versus 2017

\begin{tabular}{|l|l|l|l|l|}
\hline Procedures with ECC & 2018 & & 2017 & \\
\hline Emergency & 11,147 & $11.3 \%$ & 12,032 & $11.8 \%$ \\
\hline Redo & 8,642 & $8.8 \%$ & 9,049 & $8.9 \%$ \\
\hline
\end{tabular}


Table V1 Isolated heart valve procedures

\begin{tabular}{|l|l|l|l|}
\hline Procedure & $N$ & $\dagger$ & $\%$ \\
\hline Single valve & 16,840 & 658 & 3.9 \\
\hline Double valve & 3,233 & 285 & 8.8 \\
\hline Triple valve & 353 & 48 & 13.6 \\
\hline $\begin{array}{l}\text { Transcatheter access } \\
\text { (single valve) }\end{array}$ & 14,375 & 386 & 2.7 \\
\hline $\begin{array}{l}\text { Transcatheter access } \\
\text { (double valve) }\end{array}$ & 21 & 2 & 9.5 \\
\hline Unspecified & 93 & 10 & 10.8 \\
\hline Total & 34,915 & 1,389 & 4.0 \\
\hline
\end{tabular}

Notes: Transcatheter heart valve procedures: 13,279 aortic valve implantation; 156 mitral valve implantation; 831 mitral valve repair; 3 tricuspid valve implantation; 102 tricuspidal valve repair; 4 pulmonary valve implantation; and 21 combined aortic and mitral valves procedure.
Table V2 Single heart valve procedures

\begin{tabular}{|l|l|l|l|}
\hline Access path & $N$ & $\dagger$ & $\%$ \\
\hline Aortic valve & 6,534 & 270 & 4.1 \\
\hline Sternotomy & 3,488 & 64 & 1.8 \\
\hline Partial sternotomy & 11,654 & 272 & 2.3 \\
\hline Transvascular & 1,625 & 86 & 5.3 \\
\hline Transapical & \multicolumn{5}{l}{} \\
\hline Mitral valve & 2,819 & 208 & 7.4 \\
\hline Sternotomy & 3,403 & 48 & 1.4 \\
\hline Minimal invasive & 987 & 26 & 2.6 \\
\hline Transcatheter & 413 & 53 & 12.8 \\
\hline Tricuspidal valve & 129 & 11 & 8.5 \\
\hline Sternotomy & 105 & 2 & 1.9 \\
\hline Minimal invasive & 50 & 2 & 4.0 \\
\hline Transcatheter & 1 & 0 & 0.0 \\
\hline Pulmonary valve & 4 & 0 & 0.0 \\
\hline Sternotomy & 31,212 & 1,042 & 3.3 \\
\hline Minimal invasive & 50 & \\
\hline Transcatheter & & \\
\hline Total & & & \\
\hline
\end{tabular}

Notes: A total of 3,488 (35\%) by partial sternotomy. A total of 3,403 $(55 \%)$ mitral valve procedures by minimally invasive access. Apical aortic conduit procedures $(n=3)$ not included.

Table V3 Isolated aortic/mitral valve operations

\begin{tabular}{|l|l|l|l|l|l|l|}
\hline \multirow{2}{*}{ Prosthesis/native heart valve } & \multicolumn{2}{l|}{ Aortic } & \multicolumn{2}{l|}{ Mitral } \\
\cline { 2 - 7 } & N & $\dagger$ & $\%$ & N & $\dagger$ & \% \\
\hline Xenograft & 8,800 & 312 & 3.5 & 1,813 & 184 & 10.1 \\
\hline Mechanical prosthesis & 992 & 21 & 2.1 & 400 & 22 & 5.5 \\
\hline Repair & 193 & 0 & 0.0 & 3,999 & 49 & 1.2 \\
\hline Homograft & 37 & 1 & 2.7 & 10 & 1 & 10.0 \\
\hline Total & $\mathbf{1 0 , 0 2 2}$ & 334 & $\mathbf{3 . 3}$ & $\mathbf{6 , 2 2 2}$ & $\mathbf{2 5 6}$ & $\mathbf{4 . 1}$ \\
\hline
\end{tabular}

Note: Transcatheter procedures and apical aortic conduit procedures $(n=3)$ not included.

Table V4 Isolated/combined mitral valve procedures-implantation/replacement versus repair

\begin{tabular}{|c|l|l|l|l|l|l|l|l|l|l|}
\hline \multirow{2}{*}{ Mitral valve procedures } & \multicolumn{2}{l|}{ Repair } & \multicolumn{2}{l|}{$\begin{array}{l}\text { Implantation/ } \\
\text { replacement }\end{array}$} & \multicolumn{3}{l|}{ Total } \\
\cline { 2 - 12 } & $N$ & $\dagger$ & $\%$ & $N$ & $\dagger$ & $\%$ & $N$ & $\%$ & $\dagger$ & $\%$ \\
\hline Isolated & 3,999 & 49 & 1.2 & 2,223 & 207 & 9.3 & 6,222 & 64.3 & 256 & 4.1 \\
\hline CABG & 1,302 & 86 & 6.6 & 903 & 139 & 15.4 & 2,205 & 59.0 & 225 & 10.2 \\
\hline Tricuspid valve repair ${ }^{\text {a }}$ & 918 & 27 & 2.9 & 632 & 71 & 11.2 & 1,550 & 59.2 & 98 & 6.3 \\
\hline Aortic valve & 558 & 33 & 5.9 & 849 & 130 & 15.3 & 1,407 & 39.7 & 163 & 11.6 \\
\hline CABG + aortic valve replacement & 241 & 25 & 10.4 & 256 & 47 & 18.4 & 497 & 48.5 & 72 & 14.5 \\
\hline Total & 7,018 & 220 & 3.1 & 4,863 & 594 & 12.2 & 11,881 & 59.1 & $\mathbf{8 1 4}$ & $\mathbf{6 . 9}$ \\
\hline
\end{tabular}

${ }^{a} 57$ procedures (not specified mitral valve + tricuspid valve surgery) excluded. Mortality: 9\% (5/57). 
Table V5 Multiple heart valve procedures

\begin{tabular}{|l|l|l|l|}
\hline Combinations & $N$ & $\dagger$ & $\%$ \\
\hline Mitral + tricuspid & 1,607 & 103 & 6.4 \\
\hline Aortic + mitral & 1,407 & 163 & 11.6 \\
\hline Aortic + mitral + tricuspid & 352 & 47 & 13.4 \\
\hline Aortic + tricuspid & 168 & 19 & 11.3 \\
\hline Aortic + pulmonary ${ }^{\text {a }}$ & 37 & 0 & 0.0 \\
\hline Tricuspid + pulmonary & 14 & 0 & 0.0 \\
\hline Aortic + mitral + pulmonary & 1 & 1 & 100.0 \\
\hline Total & 3,586 & 333 & 9.3 \\
\hline
\end{tabular}

Note: Transcatheter procedures are excluded.

ancluding Ross procedures.

Table V6 Transcatheter heart valve procedures

\begin{tabular}{|c|c|c|c|c|c|c|c|}
\hline & \multicolumn{2}{|c|}{ Without ECC } & \multicolumn{2}{|c|}{ With ECC } & \multicolumn{3}{|l|}{ Total } \\
\hline & $N$ & $\dagger$ & $N$ & $\dagger$ & $N$ & $\dagger$ & $\%$ \\
\hline Aortic valve implantation & 13,190 & 336 & 89 & 22 & 13,279 & 358 & 3 \\
\hline Transvascular & 11,582 & 254 & 72 & 18 & 11,654 & 272 & 2 \\
\hline Transapical & 1,608 & 82 & 17 & 4 & 1,625 & 86 & 5 \\
\hline Mitral valve & 925 & 25 & 62 & 1 & 987 & 26 & 3 \\
\hline Repair & 777 & 13 & 54 & 0 & 831 & 13 & 2 \\
\hline Implantation & 148 & 12 & 8 & 1 & 156 & 13 & 8 \\
\hline Tricuspid valve repair & 105 & 2 & 0 & 0 & 105 & 2 & 2 \\
\hline Repair & 102 & 2 & 0 & 0 & 102 & 2 & 2 \\
\hline Implantation & 3 & 0 & 0 & 0 & 3 & 0 & 0 \\
\hline Aortic + mitral valve implantation & 20 & 2 & 1 & 0 & 21 & 2 & 10 \\
\hline Aortic valve implantation $^{a}+$ CABG & 23 & 3 & 7 & 2 & 30 & 5 & 17 \\
\hline Mitral valve implantation ${ }^{\mathrm{b}}+\mathrm{CABG}$ & 0 & 0 & 7 & 2 & 7 & 2 & 29 \\
\hline Aortic + mitral valve + CABG & 0 & 0 & 0 & 0 & 0 & 0 & - \\
\hline Total & 14,263 & 368 & 166 & 27 & 14,429 & 395 & 3 \\
\hline
\end{tabular}

Notes: Pulmonary valve implantation for congenital heart disease excluded; $12 \%$ of transcatheter aortic valve implantation (TAVI) by transapical access and less than 1\% of TAVI under the use of ECC.

${ }^{a}$ Femoral, subclavian, or transaortic access.

${ }^{\mathrm{b}}$ Transvascular and transapical access.

Table C1 Isolated CABG and combined procedures with ECC

\begin{tabular}{|l|l|l|l|}
\hline & $N$ & $\dagger$ & $\%$ \\
\hline Isolated CABG & 33,999 & 976 & 2.9 \\
\hline Aortic valve replacement & 5,668 & 273 & 4.8 \\
\hline Other & 1,749 & 106 & 6.1 \\
\hline Mitral valve repair & 1,302 & 86 & 6.6 \\
\hline Mitral valve replacement & 903 & 139 & 15.4 \\
\hline Aortic valve replacement + mitral valve repair & 241 & 25 & 10.4 \\
\hline Aortic valve + mitral valve replacement & 256 & 47 & 18.4 \\
\hline Aneurysm resection & 115 & 10 & 8.7 \\
\hline Transcatheter aortic valve implantation & 30 & 5 & 16.7 \\
\hline Total & 44,263 & 1,667 & 3.8 \\
\hline
\end{tabular}


Table C2 Isolated CABG with/without ECC

\begin{tabular}{|l|l|l|l|l|l|l|l|l|l|}
\hline \multirow{2}{*}{ Grafts } & \multicolumn{3}{|l|}{ With ECC } & \multicolumn{3}{l|}{ Without ECC } & \multicolumn{2}{l|}{ Total } \\
\cline { 2 - 12 } & $\mathbf{N}$ & $\dagger$ & $\%$ & $N$ & $\dagger$ & $\%$ & N & $\dagger$ & $\%$ \\
\hline Single & 881 & 59 & 6.7 & 1,327 & 34 & 2.6 & 2,208 & 93 & 4.2 \\
\hline Double & 5,576 & 213 & 3.8 & 1,973 & 37 & 1.9 & 7,549 & 250 & 3.3 \\
\hline Triple & 11,672 & 328 & 2.8 & 2,627 & 41 & 1.6 & 14,299 & 369 & 2.6 \\
\hline Quadruple & 6,405 & 166 & 2.6 & 886 & 13 & 1.5 & 7,291 & 179 & 2.5 \\
\hline Quintuple + more & 2,446 & 81 & 3.3 & 206 & 4 & 1.9 & 2,652 & 85 & 3.2 \\
\hline Total & $\mathbf{2 6 , 9 8 0}$ & $\mathbf{8 4 7}$ & $\mathbf{3 . 1}$ & $\mathbf{7 , 0 1 9}$ & $\mathbf{1 2 9}$ & $\mathbf{1 . 8}$ & $\mathbf{3 3 , 9 9 9}$ & $\mathbf{9 7 6}$ & $\mathbf{2 . 9}$ \\
\hline
\end{tabular}

Table Con1 Congenital heart surgery with/without ECC

\begin{tabular}{|l|l|l|l|l|l|l|}
\hline \multirow{2}{*}{ Age (y) } & \multicolumn{2}{|l|}{$\boldsymbol{N}$} & \multicolumn{1}{|l|}{} & $\%$ \\
\cline { 2 - 7 } & With ECC & Without ECC & With ECC & Without ECC & With ECC & Without ECC \\
\hline$<1$ & 2,109 & 734 & 76 & 12 & 3.6 & 1.6 \\
\hline $1-17$ & 1,800 & 210 & 14 & 0 & 0.8 & 0.0 \\
\hline$\geq 18$ & 1,048 & 27 & 32 & 0 & 3.1 & 0.0 \\
\hline Total & 4,957 & 971 & 122 & 12 & 2.5 & 1.2 \\
\hline
\end{tabular}

Table Con2 Procedures for congenital heart disease with and without ECC

\begin{tabular}{|c|c|c|c|c|c|c|c|c|c|}
\hline \multirow[t]{2}{*}{ Lesion/procedure } & \multicolumn{3}{|c|}{ Age $<1$ y } & \multicolumn{3}{|c|}{ Age $1-17$ y } & \multicolumn{3}{|c|}{ Age $\geq 18$ y } \\
\hline & $N$ & $\dagger$ & $\%$ & $N$ & $\dagger$ & $\%$ & $N$ & $\dagger$ & $\%$ \\
\hline ASD & 36 & 0 & 0.0 & 288 & 0 & 0.0 & 254 & 4 & 1.6 \\
\hline Complete AV canal & 206 & 4 & 1.9 & 91 & 0 & 0.0 & 10 & 0 & 0.0 \\
\hline VSD & 358 & 1 & 0.3 & 122 & 0 & 0.0 & 9 & 1 & 11.1 \\
\hline Fallot's tetralogy & 182 & 5 & 2.7 & 37 & 1 & 2.7 & 3 & 0 & 0.0 \\
\hline DORV & 49 & 3 & 6.1 & 19 & 0 & 0.0 & 0 & 0 & - \\
\hline TGA & 166 & 5 & 3.0 & 8 & 0 & 0.0 & 1 & 1 & 100.0 \\
\hline $\mathrm{TGA}+\mathrm{VSD}$ & 72 & 2 & 2.8 & 6 & 0 & 0.0 & 0 & 0 & - \\
\hline Truncus arteriosus & 34 & 2 & 5.9 & 5 & 1 & 20.0 & 1 & 0 & 0.0 \\
\hline Fontan circulation & 1 & 0 & 0.0 & 216 & 0 & 0.0 & 3 & 0 & 0.0 \\
\hline Norwood & 164 & 23 & 14.0 & 1 & 0 & 0.0 & 0 & 0 & - \\
\hline Pulmonary valve & 47 & 0 & 0.0 & 213 & 5 & 2.3 & 56 & 1 & 1.8 \\
\hline Transcatheter pulmonary valve implantation & 0 & - & - & 5 & 0 & 0.0 & 11 & 0 & 0.0 \\
\hline AV & 49 & 0 & 0.0 & 183 & 1 & 0.5 & 418 & 10 & 2.4 \\
\hline Ross procedure & 6 & 0 & 0.0 & 23 & 0 & 0.0 & 30 & 2 & 6.7 \\
\hline Mitral valve & 47 & 2 & 4.3 & 118 & 2 & 1.7 & 107 & 5 & 4.7 \\
\hline Tricuspid valve & 93 & 5 & 5.4 & 63 & 1 & 1.6 & 52 & 5 & 9.6 \\
\hline PDA & 188 & 3 & 1.6 & 15 & 0 & 0.0 & 0 & 0 & - \\
\hline Coarctation & 200 & 0 & 0.0 & 20 & 0 & 0.0 & 4 & 0 & 0.0 \\
\hline Others & 937 & 33 & 3.5 & 531 & 2 & 0.4 & 116 & 3 & 2.6 \\
\hline HTx & 6 & 0 & 0.0 & 34 & 1 & 2.9 & 0 & 0 & - \\
\hline HLTX & 0 & - & - & 0 & 0 & - & 0 & 0 & - \\
\hline LTx & 2 & 0 & 0.0 & 12 & 0 & 0.0 & 0 & 0 & - \\
\hline Total & 2,843 & 88 & 3.1 & 2,010 & 14 & 0.7 & 1,075 & 32 & 3.0 \\
\hline
\end{tabular}


Table Mis1 Ross procedures (autologous AV and PVR)

\begin{tabular}{|l|l|l|l|l|l|l|l|l|l|l|}
\hline Age $(\mathrm{y})$ & $\mathbf{2 0 0 9}$ & $\mathbf{2 0 1 0}$ & $\mathbf{2 0 1 1}$ & $\mathbf{2 0 1 2}$ & $\mathbf{2 0 1 3}$ & $\mathbf{2 0 1 4}$ & $\mathbf{2 0 1 5}$ & $\mathbf{2 0 1 6}$ & $\mathbf{2 0 1 7}$ & $\mathbf{2 0 1 8}$ \\
\hline$<18$ & 54 & 43 & 40 & 36 & 33 & 37 & 28 & 38 & 38 & 29 \\
\hline$\geq 18$ & 175 & 184 & 134 & 117 & 107 & 90 & 64 & 72 & 52 & 61 \\
\hline Total & 229 & 227 & 174 & 153 & 140 & 127 & 92 & 110 & 90 & 90 \\
\hline
\end{tabular}

Table Mis2 Heart and lung transplantation

\begin{tabular}{|l|l|l|l|l|l|l|}
\hline \multirow{2}{*}{ Transplant } & With ECC & \multicolumn{3}{l|}{ Without ECC } \\
\cline { 2 - 7 } & $N$ & $\dagger$ & $\%$ & $N$ & $\dagger$ & $\%$ \\
\hline HTx & 312 & 33 & 10.6 & & & \\
\hline HLTx & 2 & 0 & 0.0 & & & \\
\hline LTx & 45 & 4 & 8.9 & 295 & 10 & 3.4 \\
\hline
\end{tabular}

Notes: All pediatric transplantations (demonstrated in - Table Con2) are included in this table. Eurotransplant (ET) report $2018: 312 \mathrm{HTx}, 4$ HTx + kidney Tx, 0 HTx + liver Tx, 2 HLTx, 317 DLTx, 54 SLTx, 0 LTx + kidney Tx, and 2 LTx + liver Tx.

Table Mis3 Aortic surgery

\begin{tabular}{|c|c|c|c|c|c|c|}
\hline \multirow[t]{2}{*}{ Replacement $^{\mathrm{a}}$} & \multicolumn{3}{|c|}{ With ECC } & \multicolumn{3}{|c|}{ Without ECC } \\
\hline & $N$ & $\dagger$ & $\%$ & $N$ & $\dagger$ & $\%$ \\
\hline Supracoronary replacement of ascending aorta & 1,308 & 111 & 8.5 & & & \\
\hline Supracoronary ascending + aortic valve replacement & 1,308 & 68 & 5.2 & & & \\
\hline \multicolumn{7}{|l|}{ Infracoronary ascending } \\
\hline Mechanical aortic valve conduits & 400 & 22 & 5.5 & & & \\
\hline Biological aortic conduits & 1,062 & 113 & 10.6 & & & \\
\hline David procedure & 474 & 4 & 0.8 & & & \\
\hline Yacoub procedure & 127 & 0 & 0.0 & & & \\
\hline Other & 259 & 17 & 6.6 & & & \\
\hline Aortic arch replacement ${ }^{\mathrm{b}}$ & 2,497 & 319 & 12.8 & & & \\
\hline Replacement of descending aorta & 44 & 6 & 13.6 & 4 & 0 & 0.0 \\
\hline Thoracoabdominal aortic replacement & 81 & 7 & 8.6 & 16 & 3 & 18.8 \\
\hline Endostent descending aorta & 2 & 0 & 0.0 & 587 & 32 & 5.5 \\
\hline Total & 7,562 & 667 & 8.8 & 607 & 35 & 5.8 \\
\hline
\end{tabular}

Notes: All procedures involving aortic surgery are included in this table. Isolated aortic surgery as well as all possible combined procedures (e.g., additional coronary artery bypass grafting) are summarized in this category.

aProcedures for abdominal aortic diseases excluded: 438 , abdominal procedures and 18 , endovascular abdominal stents.

${ }^{\mathrm{b}}$ All possible combined procedures included; the only common denominator is aortic arch surgery.

Table Mis4 Pacemaker and ICD procedures

\begin{tabular}{|l|l|l|l|l|l|l|l|}
\hline \multirow{2}{*}{ Device/category } & \multicolumn{9}{|l|}{ With ECC } & \multicolumn{2}{l|}{ Without ECC } \\
\cline { 2 - 8 } & $N$ & $\dagger$ & $\%$ & $N$ & $\dagger$ & $N$ & $\dagger$ \\
\hline Pacemaker & 13,433 & 101 & 0.8 & 19 & 1 & 13,414 & 100 \\
\hline Implantation & 8,983 & 61 & 0.7 & 4 & 0 & 8,979 & 61 \\
\hline Battery exchange & 1,734 & 4 & 0.2 & 0 & 0 & 1,734 & 4 \\
\hline Revision procedures & 2,716 & 36 & 1.3 & 15 & 1 & 2,701 & 35 \\
\hline ICD & 7,382 & 73 & 1.0 & 15 & 3 & 7,367 & 70 \\
\hline Implantation & 3,194 & 11 & 0.3 & 0 & 0 & 3,194 & 11 \\
\hline Battery exchange & 1,671 & 4 & 0.2 & 0 & 0 & 1,671 & 4 \\
\hline Revision procedures & 2,517 & 58 & 2.3 & 15 & 3 & 2,502 & 55 \\
\hline Miscellaneous & 1,627 & 14 & 0.9 & 1 & 1 & 1,626 & 13 \\
\hline Total & 22,442 & $\mathbf{1 8 8}$ & $\mathbf{0 . 8}$ & 35 & $\mathbf{5}$ & $\mathbf{2 2 , 4 0 7}$ & $\mathbf{1 8 3}$ \\
\hline
\end{tabular}


Table Mis5 Surgical procedures for tachyarrhythmia

\begin{tabular}{|l|l|l|l|}
\hline \multirow{2}{*}{ Energy source } & Endocardiac & Epicardiac & Total \\
\cline { 2 - 4 } & $N$ & $N$ & 277 \\
\hline Unipolar radiofrequency & 95 & 182 & 202 \\
\hline Unipolar cryoradiofrequency & 84 & 118 & 2,266 \\
\hline Bipolar radiofrequency & 231 & 2,035 & 1,723 \\
\hline Cryothermy & 1,343 & 380 & 21 \\
\hline Microwave & 4 & 17 & 122 \\
\hline Focused ultrasound & 9 & 113 & 0 \\
\hline Laser & 0 & 0 & 24 \\
\hline Other & 13 & 11 & 2,856 \\
\hline Total & 1,779 & 2,635 \\
\hline
\end{tabular}

Note: A total of 279 procedures are unspecified with regard to endocardiac/epicardiac ablation.

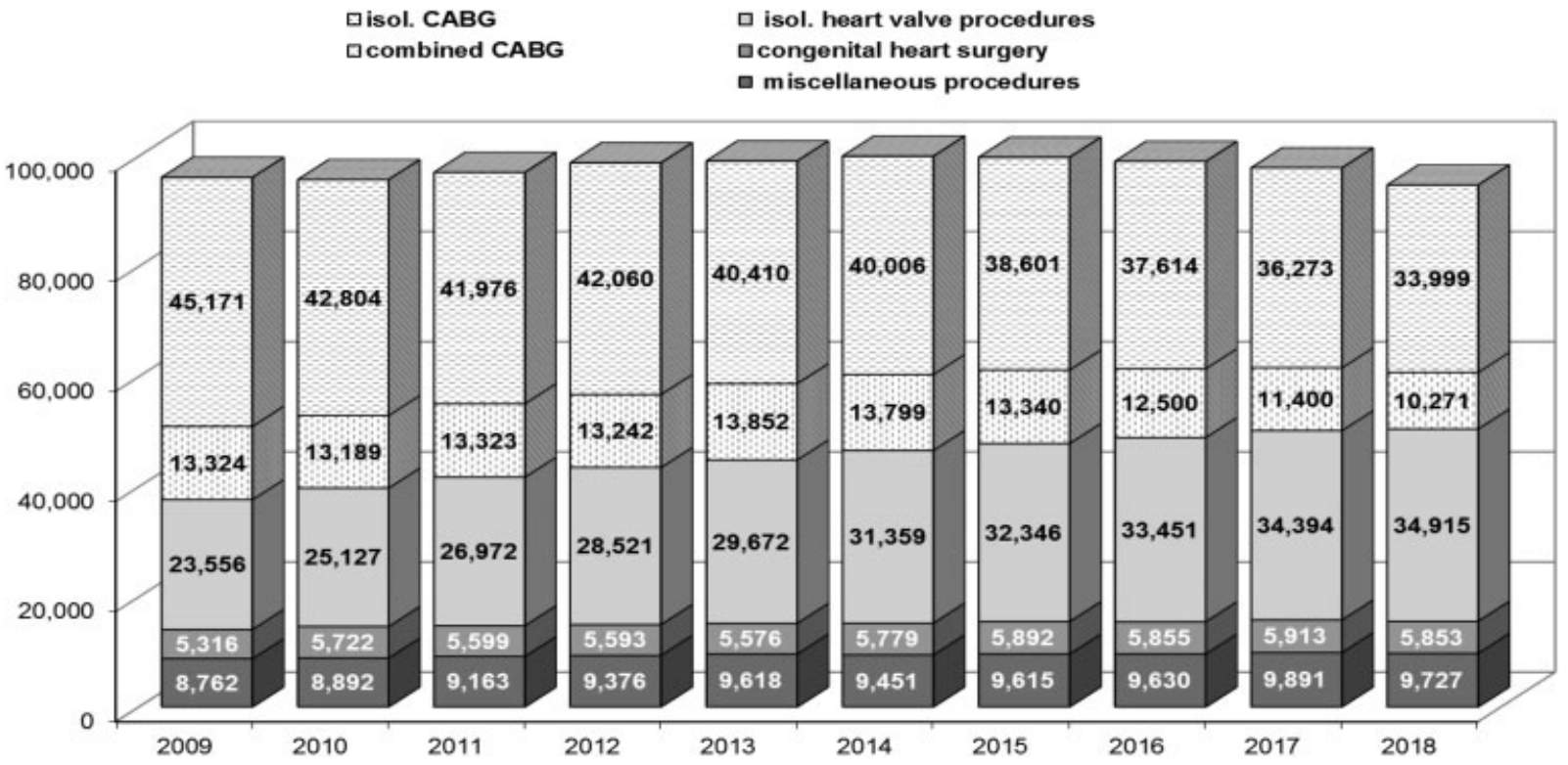

Fig. 1 Selected heart surgical categories (2009-2018). Notes: Congenital heart surgery: ASD repairs in adults or in combination with CABG or heart valve procedures are summarized in the CABG or heart valve procedure groups;miscellaneous procedures: all other types of procedures with ECC.

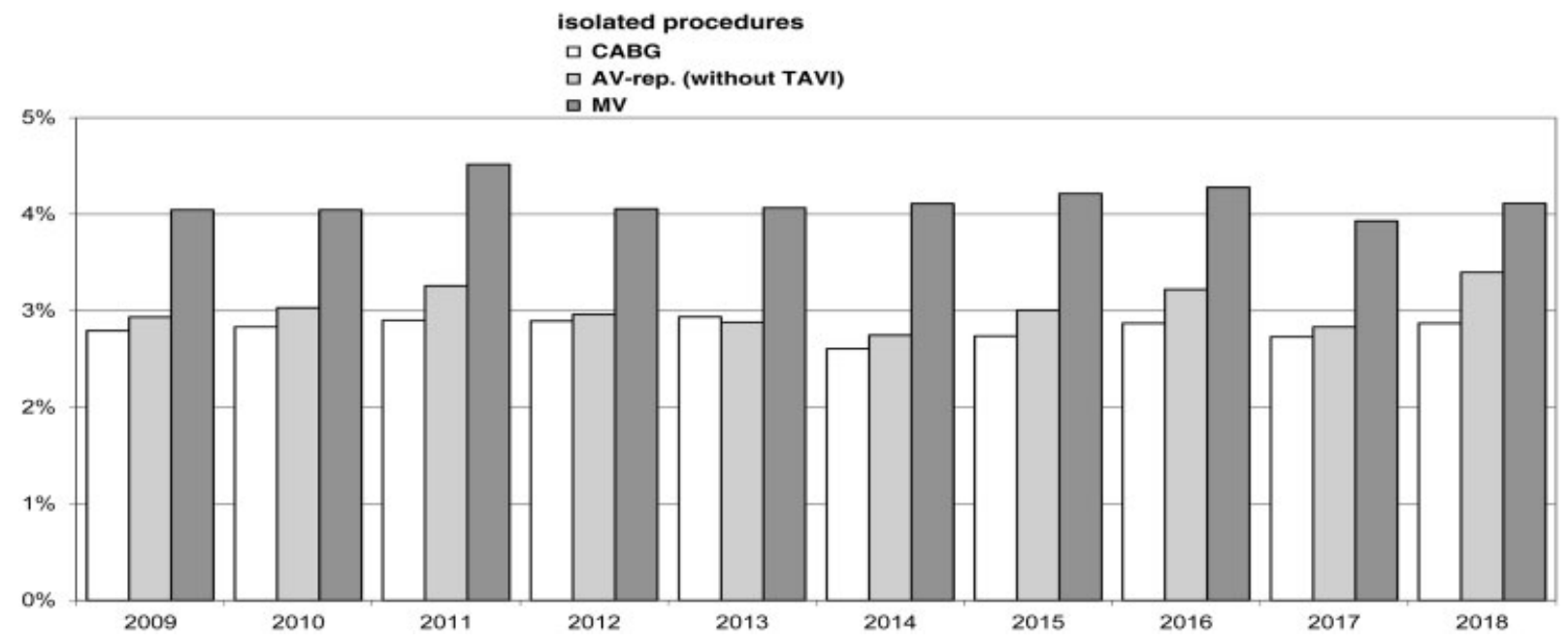

Fig. 2 Unadjusted mortality for selected procedures (2009-2018). 
$\square 20-69$ years $\square 70-79$ years $\square 80$ years and older

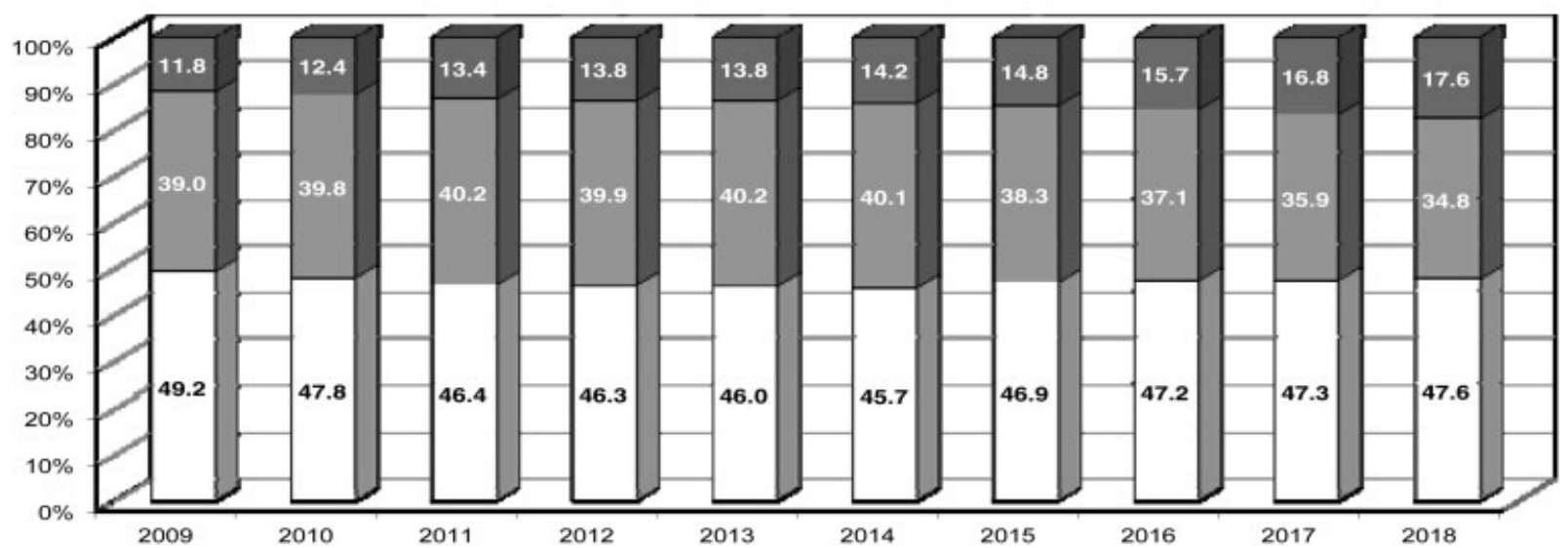

Fig. 3 Age distribution of cardiac procedures (2009-2018). Notes: patients <20 years and pacemaker/implantable cardioverter-defibrillator procedures were excluded.

$\square$ isol. on-pump CABG $\square$ isol. off-pump CABG

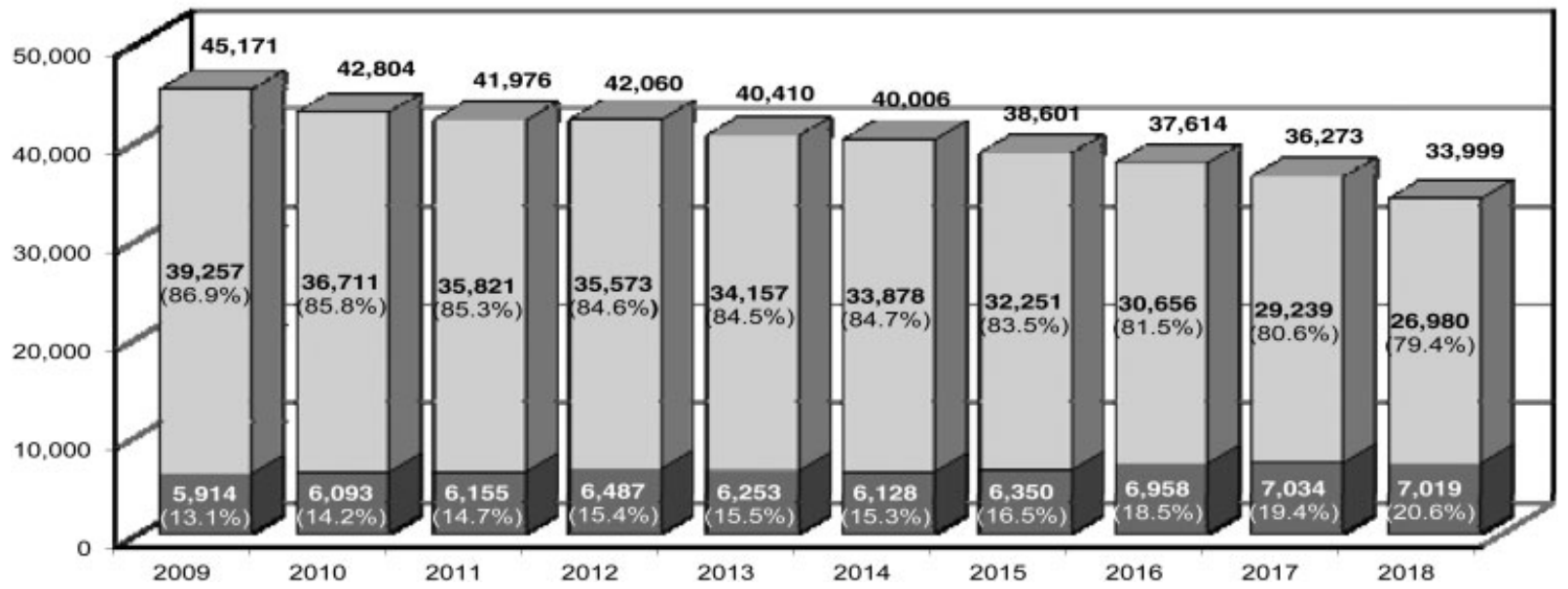

Fig. 4 Isolated coronary artery bypass grafting (CABG) (2009-2018).

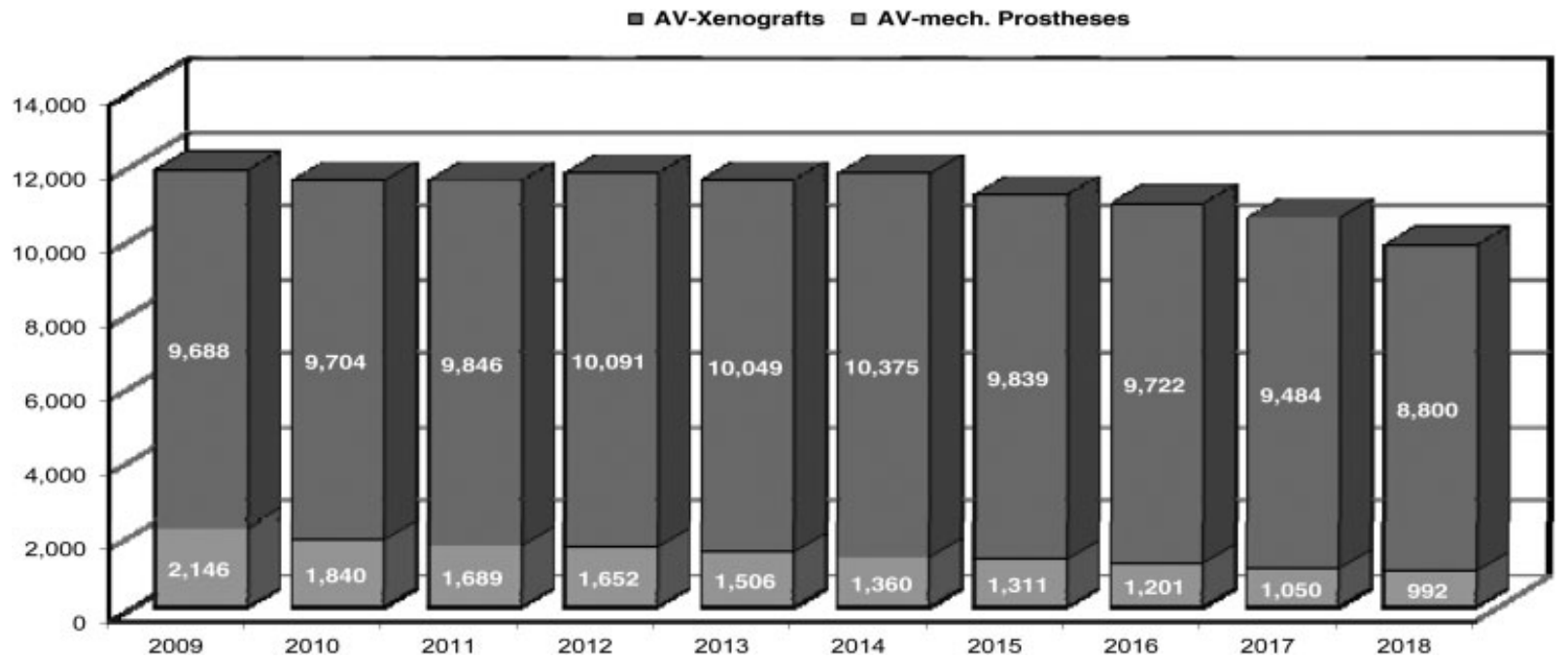

Fig. 5 Isolated aortic valve replacement (2009-2018). Notes: Ross procedures, homograft implantations, and transcatheter heart valve intervention excluded. 


\section{口TAVI aConventional}

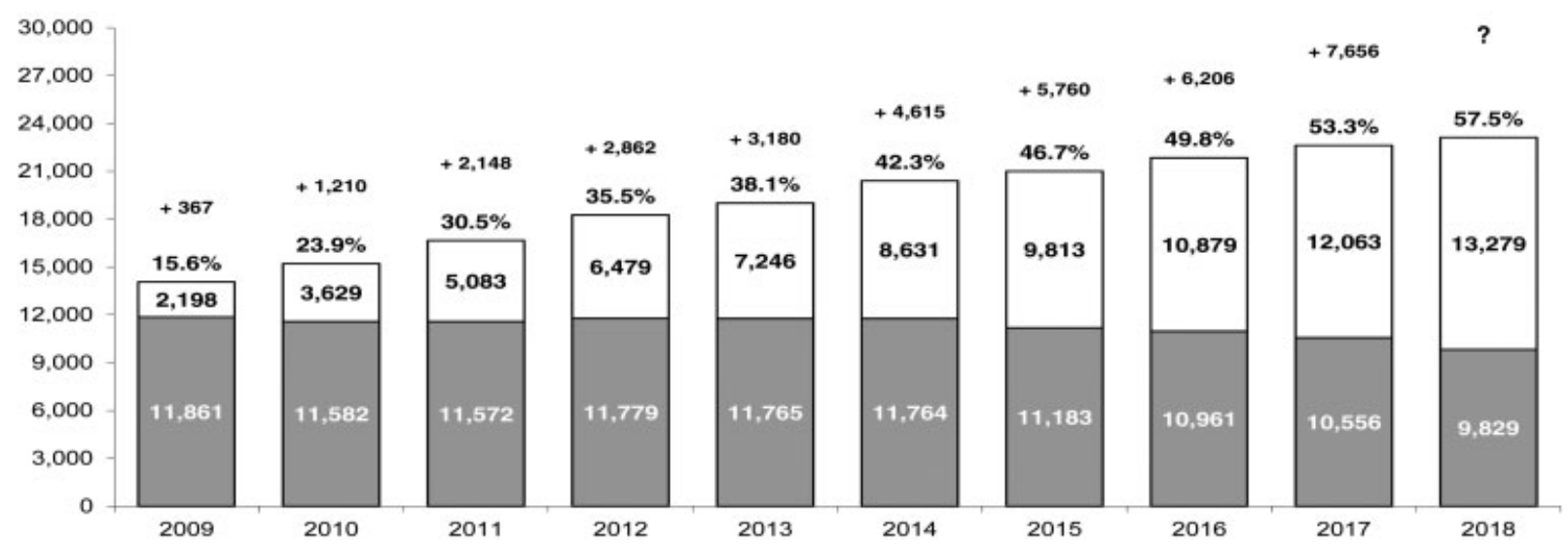

Fig. 6 Isolated aortic valve replacement and transcatheter aortic valve implantation (TAVI). The annual count of TAVI submitted to the voluntary registry of German Society for Thoracic and Cardiovascular Surgery does not represent all TAVI procedures performed in Germany in 2018. ${ }^{+}$Additional TAVI procedures calculated from the German legal quality assurance program, §§ 135a/ 136/ 137 SGB V.

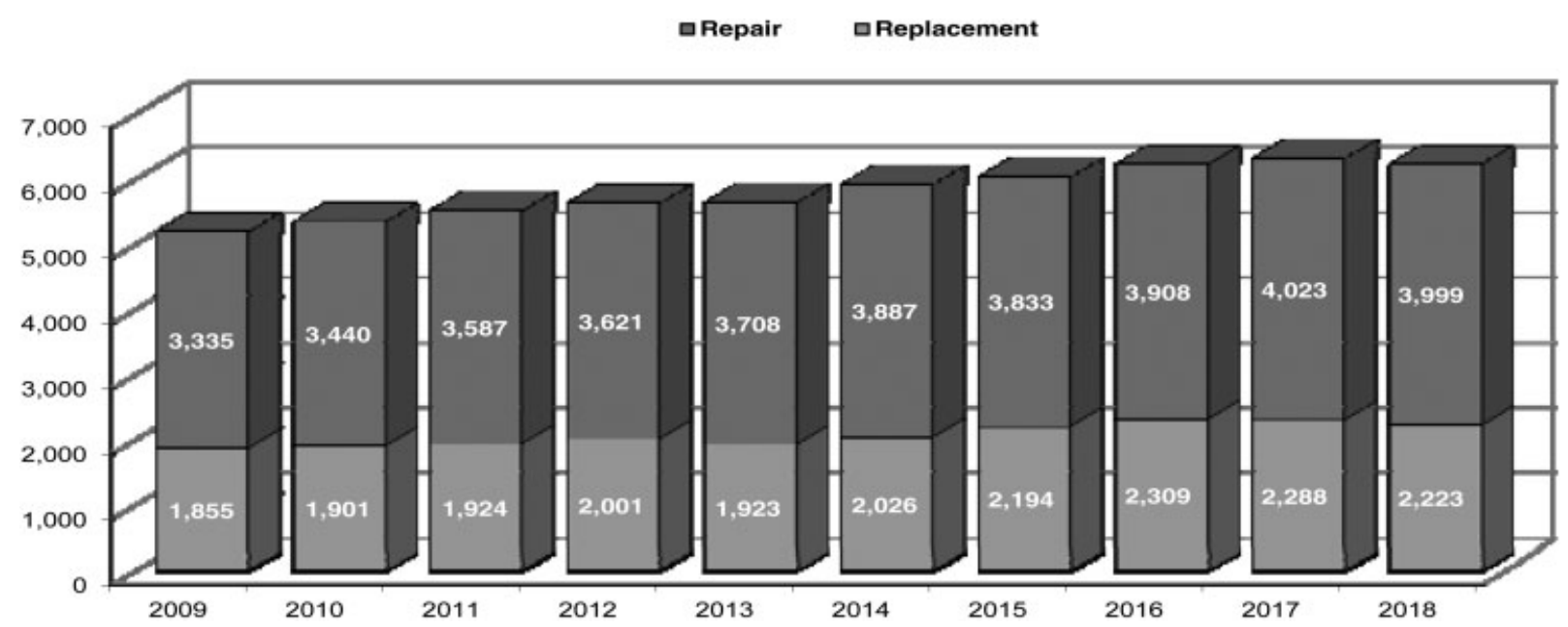

Fig. 7 Isolated mitral valve surgery (2009-2018).

$\square<1$ year $\quad \square_{1}-17$ years $\quad \square_{18}$ years and older

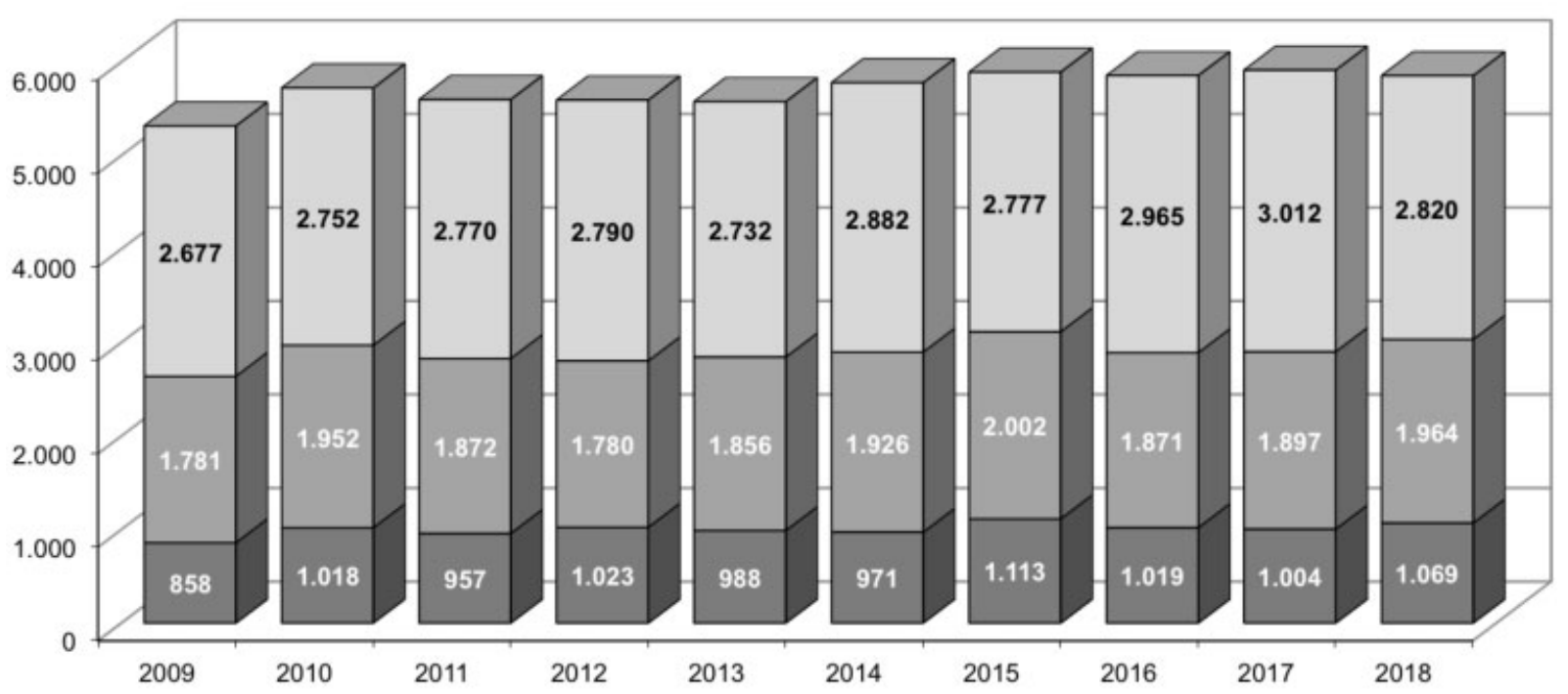

Fig. 8 Age distribution for CHD (2009-2018). Notes: Bias possible due to the fact that not all relevant procedures can be allocated exactly to CHD category in patients $>18$ years (e.g., aortic valve disease). 


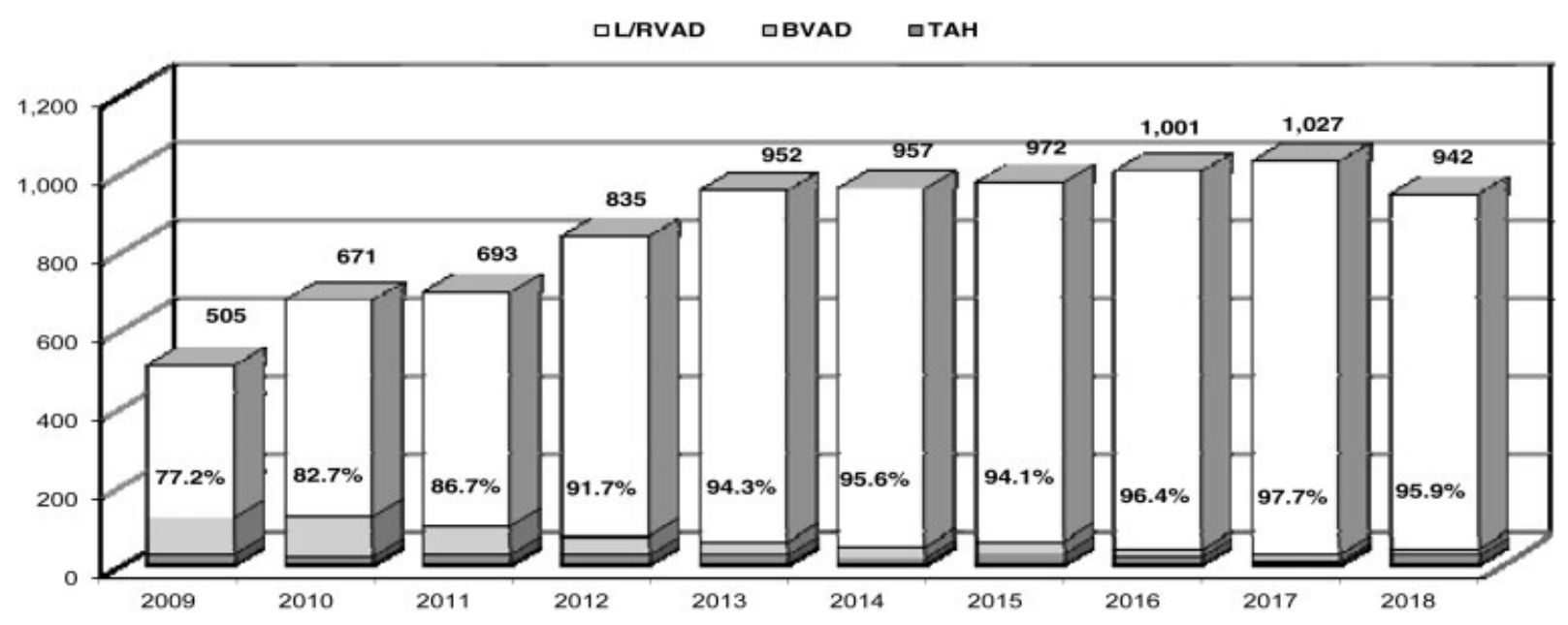

Fig. 9 Development of mechanical circulatory support (2009-2018).

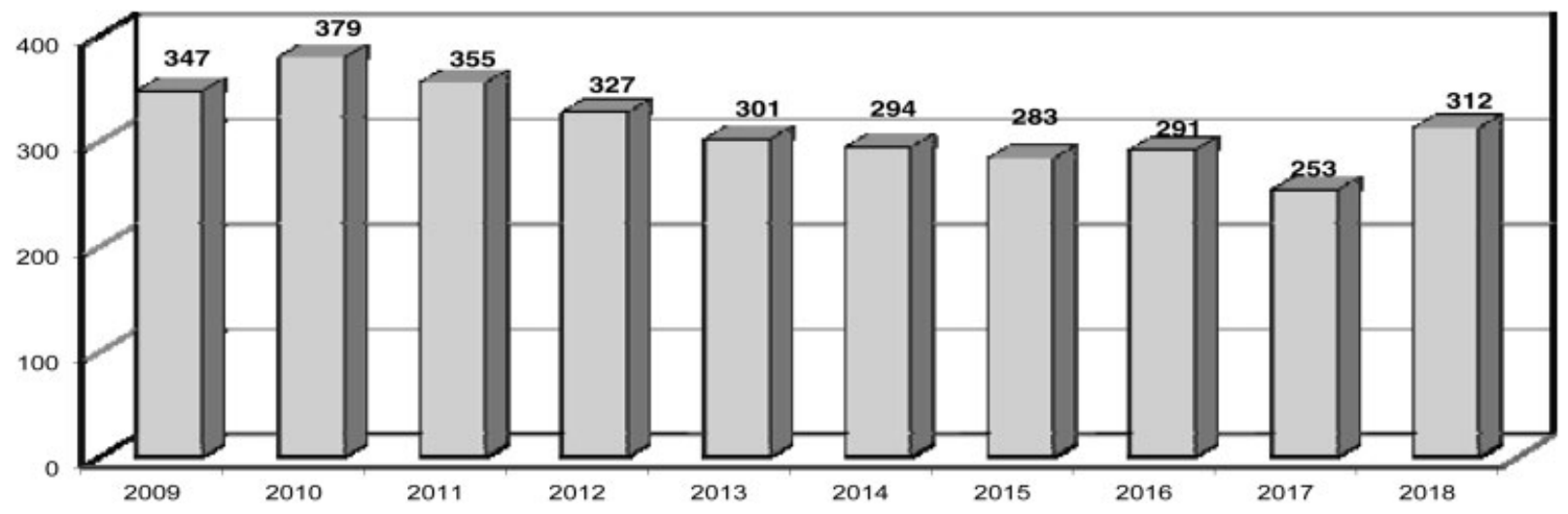

Fig. 10 Heart transplantation (2009-2018).

\section{References}

1 Rodewald G, Polonius MJ. Cardiac surgery in the Federal Republic of Germany during 1978 and 1979. Thorac Cardiovasc Surg 1980; 28(06):373-377

2 Rodewald G, Kalmar P. Cardiac surgery in the Federal Republic of Germany during 1984. Thorac Cardiovasc Surg 1985;33(06): 397-399

3 Kalmar P, Irrgang E. Cardiac surgery in the Federal Republic of Germany during 1988. Thorac Cardiovasc Surg 1989;37(03): 193-195

4 Kalmar P, Irrgang E. Cardiac surgery in the Federal Republic of Germany during 1989. A report by the German Society for Thoracic and Cardiovascular Surgery. Thorac Cardiovasc Surg 1990;38(03):198-200

5 Gummert JF, Funkat A, Krian A. Cardiac surgery in Germany during 2004: a report on behalf of the German Society for Thoracic and Cardiovascular Surgery. Thorac Cardiovasc Surg 2005;53(06):391-399

6 Funkat AK, Beckmann A, Lewandowski J, et al. Cardiac surgery in Germany during 2011: a report on behalf of the German Society for Thoracic and Cardiovascular Surgery. Thorac Cardiovasc Surg 2012;60(06):371-382

7 Beckmann A, Meyer R, Lewandowski J, Frie M, Markewitz A, Harringer W. German Heart Surgery Report 2017: the annual updated registry of the German Society for Thoracic and
Cardiovascular Surgery. Thorac Cardiovasc Surg 2018;66(08): 608-621

8 Baumgartner H, Falk V, Bax J, et al; ESC Scientific Document Group. 2017 ESC/EACTS Guidelines for the management of valvular heart disease. Eur Heart J 2017;38(36):2739-2791

9 Nishimura RA, Otto CM, Bonow RO, et al; ACC/AHA Task Force Members. 2014 AHA/ACC Guideline for the management of patients with valvular heart disease: a report of the American College of Cardiology/American Heart Association Task Force on Practice Guidelines. Circulation 2014;129(23): e521-e643

10 Nishimura RA, Otto CM, Bonow RO, et al. 2017 AHA/ACC focused update of the 2014 AHA/ACC Guideline for the management of patients with valvular heart disease: a report of the American College of Cardiology/American Heart Association Task Force on Clinical Practice Guidelines. Circulation 2017;135(25):e1159-e1195

11 Nishimura RA, O'Gara PT, Bavaria JE, et al. 2019 AATS/ACC/ASE/ SCAI/STS Expert Consensus Systems of Care Document: a proposal to optimize care for patients with valvular heart disease. Ann Thorac Surg 2019;107(06):1884-1910

12 Richtlinie zu minimalinvasiven Herzklappeninterventionen; Richtlinie über Maßnahmen zur Qualitätssicherung bei der Durchführung von minimalinvasiven Herzklappeninterventionen gemäß $\S$ 136 Absatz 1 Satz 1 Nummer 2 für nach $\S 108$ SGB V zugelassene Krankenhäuser MHI-RL; Gemeinsamer Bundesausschuss (G-BA). Available at: https://www.g-ba.de/richtlinien/84/ 
13 Beckmann A, Hamm C, Figulla HR, et al; GARY Executive Board. The German Aortic Valve Registry (GARY): a nationwide registry for patients undergoing invasive therapy for severe aortic valve stenosis. Thorac Cardiovasc Surg 2012;60(05):319-325

14 Ensminger S, Fujita B, Bauer T, et al; GARY Executive Board. Rapid deployment versus conventional bioprosthetic valve replacement for aortic stenosis. J Am Coll Cardiol 2018;71(13):1417-1428

15 Fujita B, Ensminger S, Bauer T, et al; GARY Executive Board. Trends in practice and outcomes from 2011 to 2015 for surgical aortic valve replacement: an update from the German Aortic Valve Registry on 42776 patients. Eur J Cardiothorac Surg 2018;53 (03):552-559

16 Husser O, Fujita B, Hengstenberg C, et al; GARY Executive Board. Conscious sedation versus general anesthesia in transcatheter aortic valve replacement: the German Aortic Valve Registry. JACC Cardiovasc Interv 2018;11(06):567-578

17 Werner N, Zahn R, Beckmann A, et al. Patients at intermediate surgical risk undergoing interventional or surgical aortic valve implantation for severe aortic stenosis: one year results from the German Aortic Valve Registry. Circulation 2018; 138:2611-2623
18 Bekeredjian R, Szabo G, Balaban Ü, et al. Patients at low surgical risk as defined by the Society of Thoracic Surgeons score undergoing isolated interventional or surgical aortic valve implantation: in-hospital data and 1-year results from the German Aortic Valve Registry (GARY). Eur Heart J 2018

19 Gammie JS, Zhao Y, Peterson ED, O'Brien SM, Rankin JS, Griffith BP. J. Maxwell Chamberlain Memorial Paper for adult cardiac surgery. Less-invasive mitral valve operations: trends and outcomes from the Society of Thoracic Surgeons Adult Cardiac Surgery Database. Ann Thorac Surg 2010;90(05):1401-1408, 1410.e1, discussion 1408-1410

20 Herbert MA, Prince SL, Williams JL, Magee MJ, Mack MJ. Are unaudited records from an outcomes registry database accurate? Ann Thorac Surg 2004;77(06):1960-1964, discussion 1964-1965

21 Neumann FJ, Sousa-Uva M, Ahlsson A, et al; ESC Scientific Document Group. 2018 ESC/EACTS Guidelines on myocardial revascularization. Eur Heart J 2019;40(02):87-165

22 Bundesärztekammer (BÄK), Kassenärztliche Bundesvereinigung (KBV), Arbeitsgemeinschaft der Wissenschaftlichen Medizinischen Fachgesellschaften (AWMF). Nationale VersorgungsLeitlinie Chronische KHK - Langfassung, 5 Auflage. Version 1. 2019 